\title{
Word Association Type and the Temporal Stacking of Responses
}

\author{
JOHN C. MASTERS \\ University of Minnesota, Minneapolis, Minnesota 55455 \\ Gary B. Mesibov \\ University of Michigan, Ann Arbor, Michigan 48104 \\ GARY W. ANDERSON \\ University of Minnesota, Minneapolis, Minnesota 55455
}

\begin{abstract}
In two studies, data were gathered concerning the originality and latency of word associations obtained under no instructions or under instructions to be as original as possible. Responses were scored as paradigmatic (P) or syntagmatic (S). Earlier analyses had determined that highly original responses tended to be $\mathrm{S}$. The hypothesis that instructions to be original would increase the latency of responding was confirmed. Under no instructions, $S$ responses were of greater latency than $\mathbf{P}$. However, contrary to prediction, under originality instructions the reverse was true, and further analyses revealed that $\mathrm{P}$ responses of longer latency were of significantly less originality. The results are interpreted in terms of a responsehierarchy model.
\end{abstract}

The concept of a response hierarchy (Mednick, 1962; White, 1965) generally implies a preset ordering of the associative connections between a stimulus and the several responses which it may evoke. The ordering is seen to be one of decreasing response strength (typically operationalized as response probability), such that a blocking or active inhibition of a prepotent response allows the occurrence of a weaker response in that hierarchy. A strict conceptualization of this model insists that such weaker responses may occur only upon the removal, by blocking, inhibition, or prior performance, of the more strongly associated responses. Another hypothesis generated by this model states that responses further down the hierarchy will take longer to produce, especially when the organism is forced actively to inhibit the prepotent responses. The supposition here is that the process of active inhibition of responses requires time.

Earlier work on originality in word associations (Masters \& Anderson, 1968) (M \& A) has demonstrated that instructions to be original, or additional time during which to consider an associative response, resulted in more original word associations. A second study (Masters \& Mesibov, 1968) (M \& M) found that distraction which was to be ignored tended to decrease the latency with which original responses were produced. Both of these studies could be interpreted in terms of a response hierarchy model, in which responses of greater originality lay further down on the response hierarchy and required the active inhibition of first-order associations in order to emerge.

Further analysis of these data revealed a significant relationship between the production of an original word association and the tendency for that response to be paradigmatic (P) (of the same part of speech as the stimulus) or syntagmatic (S) (a response which could precede or follow the stimulus word in a sentence). It has been shown (Ervin, 1961; Masters, 1969) that $S$ responses are more 
common among children than of adults; hence, they might be expected to lie further down in the hierarchies of word association responses in adults, since they have been superseded by $\mathbf{P}$ association. It is thus in keeping with the response hierarchy hypothesis that a relationship is found between the mean number of $P$ and $S$ responses which an individual produces and the mean originality of his responses, such that high originality is associated with a low number of $\mathbf{P}$ responses (Pearson $r$ 's of $-.56, N=40$, in the $\mathrm{M} \& \mathrm{~A}$ study and $-.45, N=48$, for the M \& M study, both significant). Greater originality is also associated with an increased number of $S$ responses ( +.54 for $\mathrm{M} \& \mathrm{~A}$, and +.23 for $M$ \& $M$, both significant). Also in keeping with the hierarchy hypothesis is the finding that the greater the originality of a response, the longer the latency in responding (Pearson $r$ 's of +.56 for $\mathrm{M} \& \mathrm{~A}$ under no instructions, +.50 for $M$ \& $M$ under no instructions, and +.47 for $M \& M$ under instructions to be as original as possible).

In keeping with the observation that $S$ responses are uncommon among adults but somewhat more characteristic of children, it seems plausible that the typical $\mathrm{S}$ response is produced only following the blocking or inhibiting of a prepotent $P$ response in adults. The production of a $S$ response, then, should require a greater amount of time to produce. As noted above, this has already been observed for original responses, which tend to be $\mathbf{S}$. Procedures which are designed to facilitate the production of original responses, such as instructions to be original in word associations, might be expected to increase the latency of both $\mathrm{P}$ and $\mathrm{S}$ responses if they are original. At the same time, however, the latency for a $S$ response in an adult should remain greater, on the average, than the latency for a $P$ response, since it was acquired during earlier learning and should appear only upon the inhibition of the $P$ association. In order to assess these hypotheses, the data from the M \& A and $M$ \& $M$ studies were reanalyzed, looking at the latency of response for $\mathbf{P}$ and $\mathrm{S}$ responding before and after procedures which increased the originality of responses.

\section{Method}

Precise details of the method of data collection are contained in the two prior studies ( $M$ \& $A$ and $M \& M$ ). The current study presents further analyses of data collected in these two experiments. The $S \mathrm{~s}$ in both experiments were students from introductory psychology classes at Stanford University. They were asked to respond to word association lists formulated by Maltzman, Bogartz, and Breger (1958). Two lists were employed in counterbalanced order.

In both experiments, $E$ first read the stimulus words for List $I$ and $S$ was required to write his associations. No instructions were given. Latencies were recorded by the $E$. Following this, the experimental manipulations for each study were effected and List II was administered. Latencies during this administration were gathered only in the $M \& M$ study. Hence, the List-II data discussed were from the $M \& M$ study only, while the List-I data were available from both studies. No instructions other than cautions concerning relevancy of response were given prior to the administration of List I. In the M \& M study, all Ss were instructed to be as original as possible in their associations to List II. The $\mathbf{M}$ \& $\mathbf{M}$ experiment also imposed several experimental conditions involving distraction during the presentation of List II, but these conditions are distinguished only for statistical purposes (to provide a nonrepeated factor) in the present analyses.

Associated responses to both lists were scored as $\mathbf{P}$ when they were of the same part of speech as the stimulus word and as $\mathrm{S}$ when a sentence could be constructed in which the response word immediately preceded or followed the stimulus word. Responses which might be either $\mathrm{P}$ or $\mathrm{S}$ were scored as .5 and are not included in these analyses. Scoring was done by the senior author, and the junior authors were consulted for every response deemed ambiguous. The responses were written and unavailable to the $E$ when the latency was recorded. The originality of a response on List II was defined in terms of a commonality score, which consisted of the number of $S$ s who, when given the stimulus word as part of List I, had emitted that same response. The commonality score for a particular response word could range from 0 (no $S$ gave that response to the stimulus word) to 20 (M \& A) or 24 (M \& M) (all subjects having that stimulus in List I gave that response). A second commonality score was also determined via the more extensive norms prepared by Palermo and Jenkins (1964).

Comparison of the latencies for $\mathbf{P}$ and $\mathrm{S}$ responses and for responses to Lists I and II involved correlated 
data. For analysis of the M \& A data, $t$ tests for correlated means were employed. For analysis in the $M \& M$ data, a $3 \times 2 \times 2$ analysis of variance was conducted with the three experimental conditions serving as the nonrepeated factor, and $\mathrm{P}$ and $\mathrm{S}$ responses and Lists $\mathrm{I}$ and II being repeated factors. Only the findings for the repeated factors will be discussed, since the experimental conditions were the subject of the earlier report. Individual group comparisons following up significant $F$ s were conducted via correlated $t$ tests.

\section{RESUlts AND Discussion}

Mean latencies for $\mathbf{P}$ and $\mathbf{S}$ responses to Lists I and II are presented in Table 1 . On the initial list, under no instructions, both studies indicated that the mean latency for $\mathrm{P}$ responses was significantly shorter than the mean $\mathrm{S}$ latency. For the $\mathrm{M} \& \mathrm{~A}$ data, $t(37)=3.75$, $p<.01$, and for $\mathrm{M} \& \mathrm{M}$ data, $t(47)=2.61$, $p<.02$.

\section{TABLE 1}

Mean Latencies of Response for Paradigmatic (P) and Syntagmatic (S) Word Associations IN the ABSENCE OF INSTRUCTIONS TO BE ORIGINAL (LIST I) AND Following Such InSTRuctions (LIST II)

\begin{tabular}{|c|c|c|c|}
\hline \multirow[b]{2}{*}{ Study } & \multirow{2}{*}{$\begin{array}{l}\text { Type of } \\
\text { response }\end{array}$} & \multicolumn{2}{|c|}{$\begin{array}{c}\text { Mean latencies } \\
\text { (sec) }\end{array}$} \\
\hline & & List I & List II \\
\hline Masters \& Anderson & $\mathbf{P}$ & 2.99 & - \\
\hline (1968) & $\mathbf{S}$ & 3.29 & - \\
\hline Masters \& Mesibov & $\mathrm{P}$ & 1.98 & 5.41 \\
\hline (1968) & $\mathbf{S}$ & 2.20 & 4.77 \\
\hline
\end{tabular}

Analysis of variance for the $M$ \& $M$ data revealed a significant effect of List, $F(1,45)=$ $73.28, p<.001$, indicating that response latencies to List II were significantly longer than those for List I. Individual comparisons revealed that this was true for both $\mathrm{P}[t(47)=$ $8.39, p<.001]$, and $S[t(47)=6.97, p<.001]$ responses. There was also a significant interaction between type of response and list, $F(1,45)=9.76, \quad p<.001$, indicating that although $\mathrm{P}$ latencies were shorter than $\mathrm{S}$ ones for List I, the reverse was true for List II. As reported above, $P$ responses had a significantly shorter latency than S responses on List I, and a second individual comparison revealed that for List II, S responses were of significantly shorter latency than were $\mathrm{P}$ responses, $t(47)=$ $2.41, p<.02$.

Thus, the hypotheses confirmed were that under no instructions, $\mathbf{P}$ responses would be produced more quickly than $\mathbf{S}$, and that under originality instructions, responses of both types would be of increased latency. Contrary to prediction, however, under originality instructions $S$ responses were produced more quickly than were $P$ responses.

At this point in the analysis, these findings do not entirely support the theoretical concept of a response hierarchy and the hypothesis that $\mathrm{P}$ and $\mathrm{S}$ responses to a stimulus are "temporally stacked" (White, 1965) in a reliable fashion. The prediction that $S$ responses would be of greater latency was predicated upon the assumption that there was a temporal stacking of associative responses, such that responses characteristic of earlier development (S) would be lower in the hierarchy; hence, they would have consistently greater latencies than responses towards the top of the hierarchy. While this was confirmed under the base-line conditions of no instructions, when $S$ s were asked to be original and presumably to sort through their hierarchies, $\mathrm{S}$ responses were emitted with shorter latencies than were responses.

How might we account for this result? Perhaps under instruction to be original, $S$ s inhibit $P$ responses in search of less common responses lower on the hierarchy, responses which are quite probably S. If, however, these responses do not satisfy an internal judgment for originality, the $S$ may begin to feel the pressure of time and select any response so that he may terminate that trial. Although no time pressure was imposed upon $S$ s under originality instruction, latencies rarely exceeded 7 or $8 \mathrm{sec}$, indicating some internal criterion for an appropriate latency. If a $S$ then 
selects a response to terminate the trial quickly, he may release his response inhibitions and select a more prepotent response, probably $\mathrm{P}$. If this reasoning is correct, under originality instructions $P$ responses should tend not only to be of longer latency, but at the same time they should be of lesser originality. In other words, although extended latencies, whether forced ( $M \& A$ ) or voluntarily taken ( $M \& M$ ), are typically associated with greater originality and $\mathrm{S}$ responding, under originality instructions, longer latencies should be associated with $P$ responding and lesser originality.

Thus, the hypothesis tested was that, under originality instructions, $\mathbf{P}$ responses would be of lesser originality (greater commonality) than $S$ responses. Commonality scores from the Palermo and Jenkins (1964) word association norms were used for this test. The hypothesis was confirmed, thus lending credence to the speculation that, under originality instructions, $S$ s search further down the hierarchy of associations, and if a satisfactory $S$ association is not found, they revert to a more common $\mathbf{P}$ association. The mean commonality scores for $\mathrm{P}$ and $\mathrm{S}$ responses to List II of the $\mathrm{M} \& \mathrm{M}$ study are 28.95 and 13.78 , respectively, $t(46)=3.26$, $p<.01$.

It is difficult, however, for the authors to allow this hypothesis uncritical acceptance. The conceptualization that many associative hierarchies are comprised of a series of $S$ responses which have been superseded by $\mathbf{P}$ responses implies that for these stimuli a $S$ response has at one time been prepotent in the developmental history of the individual. An earlier study (Masters, 1969) revealed that, although a large developmental change may be evident in the tendency to produce $P$ and $S$ responses, children in the age range of 4-6 years produce only $50 \% \mathrm{~S}$ responses. Although this percentage is reduced to $30 \%$ for children in the 7-9 age range, it is noteworthy that, even at the earlier age period, children could not accurately be described as characterized by $S$ responding. Even if children younger than age 4 were found to produce a larger proportion of $\mathrm{S}$ responses, their vocabulary is sufficiently limited so that many of the words to which adults are asked to associate are not likely to have been familiar to the child nor to have acquired a $\mathbf{S}$ association from this age period.

It is possible that the hierarchy of responding is a rule-generated hierarchy, such that adults tend to associate on the basis of semantic similarity because they have been taught to do so. Masters (1969) found a significant relationship between the tendency for children to define words functionally and their tendency to produce $\mathrm{S}$ responses. This relationship was predicted from the hypothesis that the transition from $\mathbf{S}$ to $\mathbf{P}$ responding is motivated, in part, by the training children receive in schools and from their adult companions to define words in terms of equivalents or synonyms, rather than functionally. Originality instructions may inhibit the acquired tendency to produce $\mathrm{P}$ responses, allowing the response to be selected or generated by another means: syntactic connection between stimulus and response.

Thus, it is possible that the criterion a $S$ uses to select and emit an "original" response is not his subjective estimate of its commonality, but rather whether it is $\mathrm{P}$ or $\mathrm{S}$. Given that responses are arranged in a hierarchy beginning with $\mathbf{P}$ responses, the results reported do not allow us to judge whether a $S$ selects his response by commonality or response-type criteria. Responses produced within highly similar latency periods should contain $\mathbf{P}$ and $\mathbf{S}$ responses of equivalent originality if a commonality (originality) criterion was employed by the subject, such that he emitted a response which was judged as satisfactorily original, regardless of its type. If, however, a $S$ judges by responsetype, $S$ responses should be of greater originality since they tend to be less common among adults.

Although these analysis could be conducted on the present data, it was felt that the limited number of $S$ s (48) and stimulus words (25 in each list) from the $M \& M$ study would not allow a sufficiently stable sample of responses 
from within a homogeneous latency range. It seems preferable to suggest that a replication study be run, employing two counterbalanced word lists of greater length and a greater number of Ss. Such a study would gather associations to List I, under no instructions, and to List II, under instructions to be as original as possible. Analysis testing the above hypothesis might investigate the originality of $\mathbf{P}$ and $\mathbf{S}$ responses with latencies closest to each particular $S$ 's mean response latency for each list. A larger list of stimulus words would be more likely to generate such a sample containing several $P$ and $S$ responses.

\section{REFERENCES}

ERVIN, S. Changes with age in the verbal determinants of word association. American Journal of Psycho$\log y, 1961,74,361-372$.
Maltzman, L., Bogartz, W., \& Breger, L. A procedure for increasing word association originality and its transfer effect. Journal of Experimental Psychology, 1958, 56, 392-398.

MAsters, J. C. Word association and the functional definition of words. Developmental Psychology, 1969, 1, 517-519.

MASTERS, J. C., \& ANDERson, G. W. Delay and instructions as determinants of originality in word associations. Journal of Verbal Learning and Verbal Behavior, 1968, 7, 432-433.

Masters, J. C., \& Mesibov, G. B. Distraction and originality in word associations. Journal of Verbal Learning and Verbal Behavior, 1968, 7, 1117-1119.

MEDNICK, S. A. The associative basis of the creative process. Psychological Review, 1962, 69, 220-232.

Palermo, D. S., \& Jenkins, J. J. Word Association Norms; Grade School Through College. Minneapolis: University of Minnesota Press, 1964.

WHITE, S. H. Evidence for a hierarchial arrangement of learning processes. In Lipsitt, L. P. \& Spiker, C. C. (Eds.) Advances in Child Development and Behavior, Vol. 2. New York: Academic Press, 1965.

(Received October 7, 1969) 